IRA-International Journal of Education \&

Multidisciplinary Studies

ISSN 2455-2526; Vol.17, Issue o3 (Q3, 2021)

Pg. no. 143-149.

IRA Academico Research

\title{
Interpreting Core Competencies of English as a Subject in China
}

Juan Ma (iD)

School of Foreign Studies, Yangtze University. Hubei, 434023 PRC China.

Type of Work: Peer Reviewed.

DOI: 10.21013/jems.v17.n3.p4

DOI URL: https://dx.doi.org/10.21013/jems.v17.n3.p4

How to cite this paper:

Ma, J. (2021). Interpreting Core Competencies of English as a Subject in China. IRA-International Journal of Education \& Multidisciplinary Studies (ISSN 2455-2526), 17(3), 143-149. DOI: https://dx.doi.org/10.21013/jems.v17.n3.p4

(C) IRA Academico Research.

(c) EY-No 4.0 International License subject to a proper citation to the publication source of the work.

Disclaimer: The scholarly papers as reviewed and published by IRA Academico Research are the views and opinions of their respective authors and are not the views or opinions of IRA Academico Research. IRA Academico Research disclaims any harm or loss caused due to the published content to any party.

IRA Academico Research is an institutional publisher member of Publishers International Linking Association Inc. (PILA-CrossRef), USA. IRA Academico Research is an institutional signatory to the Budapest Open Access Initiative. Hungary advocating the open access of scientific and scholarly knowledge. IRA Academico Research is a registered content provider under Open Access Initiative Protocol for Metadata Harvesting (OAI-PMH).

The journal is indexed \& included in WorldCat Discovery Service (USA), CrossRef Metadata Search (USA), WorldCat (USA), OCLC (USA), Open J-Gate (India), EZB (Germany) Scilit (Switzerland), Airiti (China), Bielefeld Academic Search Engine (BASE) of Bielefeld University, Germany, PKP Index of Simon Fraser University, Canada. 


\begin{abstract}
The proposal of core competencies of English subject conforms to the goal for talent training, which puts forward higher requirements for English teaching. The core competencies of English subject include language ability, learning ability, thinking quality and cultural awareness. It emphasizes the development of students' core competencies, the cultivation of students' correct values and attitudes, and the realization of the educational value of English subject. Interpretation of the core competencies of English subject helps teachers to grasp teaching better and deeply, which will be useful for teachers to clearly apply the theories into teaching design, so as to achieve the purpose of educating people in English subject. This article interprets the core competencies of English subject in China and explains the meaning of related concepts: activity view on English learning and English subject ability. On this basis, this thesis will take a teaching design of a reading text in unit 5 in the $4^{\text {th }}$ compulsory English book for senior high school students published by People's Education Press as an example, to illustrate the realization of the core competencies of English as a subject in senior high school English reading teaching, which aims to provide enlightenment for teachers' English reading teaching in senior high school in China.
\end{abstract}

Keywords: China, core competencies of English subject, interpretation, senior high English book, reading

\title{
1. Introduction
}

In September 2016, the framework of core competencies was put forward, demonstrating a new stage of Chinese curriculum reform of elementary education. Compared with the old version that emphasizes the ability of comprehensive language use, the new version pays more attention to the educational value of English subject. Aiming at changing the phenomenon of excessive attention to vocabulary and grammar teaching in traditional English teaching, the new curriculum puts forward the goal of emphasis on the educational value of English courses and cultivating students' qualities and values. Regarding the reform of the teacher-oriented classroom in traditional teaching, the new curriculum advocates an evaluation method that takes students as the main part of classes and comprehensively uses multiple evaluation methods to assess student performance and grades. For the problem of fragmented teaching content, the new curriculum advocates that teachers start teaching from themes and design the teaching with the unit as a whole. On this basis, the new curriculum emphasizes the cultivation of students' correct values and life attitudes based on humanistic characteristics of English course, and develops students' independent learning, autonomous learning and lifelong learning ability, cultivates students' sense of social responsibility so that students can become talented with patriotic feelings, international vision and world horizon. Starting from the above goals, English teachers and English teaching should be guided by the aim of cultivation of students' core competencies, and help students form the necessary qualities and key abilities for life and learning. Through changes in course structure, content, teaching methods and evaluation methods, the educational value of the English subject can be realized and the core qualities of students can be developed.

\section{Definitions of Related Concepts}

English teachers in China take responsibility for cultivating students' core competencies so as to achieve the purpose of educating people of English subject. However, due to the theoretical and abstract characteristics of core competencies, many teachers are still confused about how to apply core competencies education into teaching practice. In response to this problem, English Curriculum Standards for Senior High School clearly puts forward the activity view of English learning. Through the design and implementation of hierarchical activities, teachers can apply the concept of core competencies to teaching practice, thereby promoting the development of students' core competencies. Moreover, the design of activities should not be random but are carefully arranged according to the teaching content and characteristics of students. Activities designed from simple to difficult, and from lower level to higher level of cognition, can gradually develop students' learning ability and thinking capacity. Accordingly, the project team of "Study on Performance of Subject Ability in Primary and Secondary Schools" put forward the conception of subject ability, which provides a more specific and feasible framework for teaching practice under the goal of cultivating core competencies. The following content will be the interpretation of core competencies of English subject, activities view of English learning and English subject ability.

\subsection{Core Competencies of English Subject}

English Curriculum Standards for Senior High School gave the definition of core competencies of English subject - core competencies of English subject, including language knowledge, cultural knowledge, language 
skills and learning strategies, is an epitome of correct value, necessary moral character and key ability that formed through the learning of English (The Ministry of Education of the People's Republic of China, 2017). For the change of value orientation of English teaching, teachers can make the following understanding: On the one hand, under the background of global development, core competencies of English subject are the answer for "what kind of people teachers are going to educate." In the context of globalization, English is no longer just a tool to learn for Chinese students, but a subject that should pay more attention to humanity. The character of humanism of English subject has important educational functions like other liberal arts such as Chinese and history. Paying attention to the humanity of English subjects, carrying out the fundamental task of fostering character and civic virtue, and cultivating students with world vision, a sense of national pride and correct values are the responsibility of English teachers. On the other hand, the introduction and implementation of the core competencies of the English subject are of great significance to the lifelong development of a student. For senior high school students, high school education is not only a critical period to measure whether they can enter colleges, but also an important stage in the formation of values and quality development. At this stage, to lay a good foundation for English knowledge and ability, to develop students' international vision, thinking ability, innovation ability and correct outlook on life and values through English course, students can benefit a lot from future learning and life. Based on the premise of the concrete goal of cultivating students' core competencies of English subject, Chinese English teaching integrates the six elements of theme context, text type, language knowledge, cultural knowledge, language skills and learning strategies. The integration of content helps to improve the fragmentation of traditional teaching content and the stiff emotional and attitude education. Knowledge learning, ability training and emotional attitude improvement are complemented by each other, which creates contexts for language learning, and offers platforms for the development of student ability. It also provides favourable conditions for the improvement of emotional and attitude education.

\subsection{Activity View of English Learning}

English learning in the classroom is carried out through one activity after another. In a sense, activities are the main way for students to learn English in the classroom. Deming Mei pointed out: Activities are the main way for students to understand and express meaning, develop thinking, cultivate students' cultural awareness and gradually form learning ability (Mei, 2018). Traditional English learning activities focus on language knowledge, and most of the activities adopted in the classroom are exercise activities involving students' memory and understanding. Through continuous repetition and recitation, students have a relatively deep grasp of language knowledge in order to deal with the most basic obstacle encountered in language output-what to say. However, its disadvantages are also very obvious. The boring repetitive exercises not only consume the enthusiasm and interest of students in English learning but also make students' creativity nowhere to be done. Activity view of English learning based on core competencies emphasizes the guidance of theme and the support of text, and activities are the bridge connecting the two, which emphasizes the creation of a real or more authentic context for students to help students learn and understand English meaningfully in the context. Shike Cheng summarized three stages of reading teaching according to views on English learning activities, including deeply analyze the text, setting hierarchical teaching objectives by integrating the teaching content, and designing activities based on the teaching objectives (Cheng, 2019). Teaching activities designed based on the activity view of English learning can create language learning contexts for students. To output language through authentic language activities, students can be in the dominant position in learning, which can maximize their creativity, and cultivate students' core competencies.

\subsection{English Subject Ability}

Combining the characteristics of teaching in China, the main project team of "Study on Performance of Subject Ability in Primary and Secondary Schools" puts forward the subject ability performance framework in three dimensions from nine aspects: learning and understanding, application and practice, and transformation and innovation. Activities related to learning and understanding includes perception and attention, acquisition and organization, summary and integration. Activities involved in application and practice are description and interpretation, analysis and judgment, internalization and application. Activities related to transformation and innovation is reasoning and argumentation, criticism and evaluation, imagination and creation. The teaching activities are designed according to the progressive relationship between students' knowledge and ability development, which embodies the belief of English teaching that integrates knowledge acquisition, ability cultivation and emotional edification. Moreover, this progressive activity design can gradually develop students' learning ability and thinking, which shows the function of English as a subject in cultivating students' core competencies. Under the guidance of developing English subject ability, teachers gradually improve students' learning ability and core competencies and realize the educational value of the English subject in the English 
classroom by integrating elements into teaching activities.

\section{Interpretation of Core Competencies of English Subject}

\subsection{Interpretation of Language Ability}

Language ability is a basic and necessary ability for learners to learn a language. Language ability is like the foundation of a building. Only by constructing a solid foundation, the building will be more stable. Language ability refers to the ability to understand and express meaning in a social context by way of listening, speaking, reading, viewing, and writing, and also includes language awareness and a feel for language developed in the course of learning and using English (The Ministry of Education of the People's Republic of China, 2017). Some scholars consider that language ability mainly refers to the ability to understand and express with the help of language in social situations, and language ability is the "core" of the core literacy of the English subject. Language occurs in a context, and language depends on context, and context creates language (Cheng \& Zhao, 2016). Providing students with a real or close-to-real context can help students understand language more deeply, thus providing students with easier and more implementable output, so as to alleviate the boring feeling of traditional rote learning to students. Therefore, language ability is a significant ability and basis in the cultivation of core competencies of English subject. Language competence includes language knowledge, discourse knowledge and pragmatic knowledge. At a micro level, language knowledge can be subdivided into phonetic, vocabulary, and grammar knowledge. Discourse knowledge covers students' understanding and response to the text, that is, critically looking at and analyzing the content of the text. In addition, in the view of Haiping Gong, on the one hand, pragmatic knowledge refers to autonomously encodes utterance elements and outputs utterances according to pragmatic rules; on the other hand, it refers to regulate and analyze utterances according to pragmatic rules not simply meet with the grammatical correctness of the utterance(Gong, 2018) In other words, pragmatic knowledge includes not only to produce utterances that conform to grammatical rules, to pay attention to the understanding and use of language, but also includes judgement and perception of the appropriateness and suitability of the produced utterances, and euphemism of language expression.

From the above classification of the compulsory four Unit5 Reading Theme parks- fun and more than fun, a conclusion can be drawn that: Firstly, the vocabulary and phrases that students are required to master during the compulsory stage of high school in this text are: various, cartoons, be famous for, whichever, fantasy amusement, attractions, no wonder, tourism, wherever, unique, carpenters, engine, preserve, deeds, be modelled after, swords, tournament and related vocabulary collocation and usage. Secondly, the included grammatical knowledge includes the main word formation in English: compound words, derivation, and transformation. Thus, teachers can design activities such as listing the relevant vocabulary involved in the text for students to summarize the rules of word-formation. Or let students first explain the concept of word formation and then find relevant vocabulary based on the definition to deepen their understanding. Moreover, it is also a way to explain vocabulary by using the form of multimedia such as pictures and providing context for them to learn vocabulary and phrases. Beyond that, it's advisable for teachers to encourage students to make up sentences or a short paragraph by imagining they are in a theme park and thinking about what they can see and play. Hence, teachers can create a relatively authentic learning context for students to learn vocabulary and phrases. Teachers also can encourage students to draw a word mind map related to theme parks, and search for more words about theme parks and make the presentation in front of the class.

As for discourse knowledge, the text is similar to an advertisement. According to the characteristics of the text form, teachers can let students guess the theme of the passage through reading and find out the language characteristics of the advertisement. This passage put forward the theme by giving examples. Thus, students can summarize the structure by reading and answer the question such as: how is the passage organized. More specifically, students can be encouraged to make a mind map by generalizing the content. For example, the text introduces three theme parks: Disneyland, Dollywood and Camelot by showing the theme of the parks, objectives tourists can see in the parks, and activities that tourists can take part in. Teachers can carefully guide students to generalize the content by asking questions such as: what's the theme of each park? What objectives can tourists see in each park? What activities can tourists take part in? students also are encouraged to make a table in groups. Finally, draw a creative mind map based on the theme of each park. Based on the mind map, the logic of the passage can be shown to students, which can help students better understand and grasp the mainline and text characteristics of the text. Finally, starting from a pragmatic perspective, teachers can create situations to promote writing through reading. Teachers can encourage students to create advertisements with their ideas to apply what they have learned in this lesson. For example, teachers can create a situation first, that is, the 
Jingzhou City Government vigorously advocates cultural promotion, so Jingzhou Fangte Theme Park now needs to select an English advertisement to carry out cultural promotion for it. Then, the student can brainstorm the writing material and structure about Jingzhou Fangte Theme Park. At the same time, in order to expand students' background knowledge of writing, teachers also can introduce things and activities that reflect the culture of Chu and the pictures or videos of Fangte in Jingzhou to help students write.

\subsection{Interpretation of Learning Ability}

Learning ability refers to the ability of students to learn how to learn. learning ability refers to students' awareness and ability to actively use and actively adjust English learning strategies, broaden English learning channels, and strive to improve English learning efficiency(The Ministry of Education of the People's Republic of China, 2017). Cheng Xiaotang and Zhao Siqi also pointed out that learning ability as a core competence is not limited to learning methods and learning strategies, but also include knowledge and attitudes towards English and English learning (Cheng \& Zhao, 2016). The mastery of learning ability has a great influence on students' enthusiasm for English learning. People with high learning ability can master knowledge more systematically and profoundly, and a virtuous circle is formed between the two, which effectively promotes students' learning. Therefore, it is very necessary to focus on the cultivation of learning ability in English teaching.

In English teaching, teachers can cultivate and improve students' learning ability by designing activities under the guidance of activity view on English learning. For example, in the passage of Theme parks- fun and more than fun, teachers can ask students to reason about the genre and form of the text based on the structure and language features of the article and to infer the cultural factors contained in the supplementary resources, which will be helpful to cultivate students' ability of reasoning. Teachers can also use mind maps to collect and organize information by allowing students to design mind maps, at the same time, to develop cognitive strategies to help students better understand the meaning of the text by understanding the main content and writing intention of the text according to the text type.

\subsection{Interpretation of Thinking Capacity}

Guming Xia believes that thinking is the brain's indirect generalization of "objective things and connections". It is based on perception and the procession of perceptual information through intellectual activities such as analysis and synthesis, abstraction and generalization. And use the knowledge stored in memory as a medium to explore the internal essential connections and regularities of things (Xia, 2018). The biggest difference between humans and animals is that humans have the ability of thinking. Children of different ages have different thinking characteristics. According to Piaget's four stages of cognitive development, high school students are in the stage of formal operation stage, which shows characteristics of proficient thinking ability in abstract logic and the ability of generalization. They can separate themselves from form and content and transcend dependence on concrete objects. Therefore, in English teaching, teachers should not only pay much attention to the transfer of knowledge, but also need to careful arrangement in the design of problems and the organization of activities, so as to effectively train students' thinking capacity and enhance students' logical thinking, critical thinking, and the ability of creativity.

In this text, teachers can carefully guide students to compare the similarities and differences of the three theme parks based on the mind maps made by their groups and analyze and summarize the characteristics of theme parks. In this activity, students will first find that the three theme parks reflect different themes by comparison, and things and activities will have their own characteristics accordingly. Second, although the three parks have different themes, the similarity of the three parks is that they all have their own themes-specific cultures, which is the culture of each park reflected in objects and activities. Thus, teachers can lead students to think about what's the meaning of visiting a theme park, and whether a theme park is just a place for people to entertain. Students may come out some points such as theme parks contain specific cultures, and theme parks are amazing places where people can know more about culture through visiting the parks and enjoying the activities, thereby students can interpret the author's intention in writing the passage, that is to feel the charm of culture during the process of entertainment in theme parks. In this process, through sorting and analyzing information, the logic of students' thinking can be effectively exercised. At the same time, based on the in-depth understanding of the text, students are asked to create an advertisement combining the structure and language characteristics of advertisements they have mastered with the information of Fangte theme parks supplemented by teachers. In the process of creation, teachers need not only to guide students to pay attention to the structural characteristics and language characteristics of the advertisement but also need to encourage students to use their imagination to write advertisements with their own unique creativity. For example, students can create 
advertisements based on the scenery that can be viewed, the facilities that can be played, and the special delicacies that can be eaten under a particular theme. Students can also start drafting from different audiences of the advertisement such as for children, adults, and for the elderly. Such activities can not only encourage students to internalize and transfer the language knowledge they have learned, but also provide good opportunities for the development of students' creativity, and reach the highest level of English subject ability-transference and innovation.

\subsection{Interpretation of Cultural Awareness}

Cultural knowledge includes Chinese and foreign cultural knowledge, which is the basis for students to understand cultural connotations, to compare cultural similarities and differences, to absorb cultural essence, and to strengthen cultural self-confidence in language learning activities(The Ministry of Education of the People's Republic of China, 2017). Cultural knowledge covers both material and spiritual aspects. Learning a language will inevitably involve the culture because language itself is the carrier of culture. Through the study of English, students are expected to compare, appreciate, criticize, and reflect on different cultures while understanding, feeling and experiencing excellent Chinese and foreign cultures, so as to broaden their international horizons and improve their ability of cultural appreciation and tolerance, enhance the understanding of the excellent Chinese culture, form correct values, and cultivate students' civilized quality and sense of social responsibility.

In the text of Theme parks-fun and more than fun, through the understanding of "more than fun" in the title, it is not difficult to find that the so-called more fun actually comes from the understanding of the unique culture behind different themes parks. In addition, the passage involves much cultural knowledge, which will be accessible to cultivate learners intercultural competence by noticing, understanding and comparing different themes of different theme parks at home and abroad.

For example, the Disneyland theme park is created on the theme of cartoon characters created by Walt Disney Pictures, which illustrates a kind of movie culture. Dollywood is a theme park created with the theme of the culture of southeastern United States, showing a unique local culture. Camelot is a theme park with King Arthur and the Knights of the Round Table as the background, presenting the history and culture of ancient England. Compared with Dollywood and Camelot, students may know more about Disneyland. By doing so, students' cultural awareness can increase, Therefore, on this basis, teachers can help students understand the cultural information contained in these three theme parks through text, pictures or videos. In addition, teachers can also appropriately supplement the information of representative theme parks at home and abroad and other theme parks involved in this unit to help students understand the meaning of the title, and expand students' knowledge and increase their ability of cultural tolerance. At the same time, while paying attention to cultural input, students are required to learn and use English to introduce the excellent traditional Chinese culture in accordance with the requirements of cultural output. In this text, Students can take Fangte theme park in Jingzhou as an example, and use the information learned in this lesson and the information provided by the teacher as a scaffolding to finish their writing, which can effectively help students build their own "stage" to create their works with personal characteristics, thereby enhancing students' awareness and sense of pride of the excellent Chinese culture.

\section{Conclusion}

To sum up, learning English is not just the learning of a kind of language or a certain culture. English learning includes not only the learning and mastering of language knowledge and skills, but also the cultivation and improvement of learning ability, thinking quality, and cultural awareness. Cultivating these abilities and qualities needs to be achieved through accumulation bit by bit. At the same time, cultivating core competencies of English subject also requires teachers' deep interpretation of the core competencies, and to improve students' ability and qualities through carefully designing teaching activities. Through the analysis of the lesson examples of reading Theme parks-fun and more than fun, it is obvious that the reading texts in English textbooks are very useful for the comprehensive training of students' core competence in English subject, especially for the development of learning ability, thinking quality, and cultural awareness. Grasping the key points of teaching reading lessons are of great significance to the cultivation of students' core competencies of English subject. 


\section{References:}

[1]. Dao Yiliu (2017). The $4^{\text {th }}$ Compulsory English Book for Senior High School Students Published by People's Education Press [M]. Beijing, People's Education Press. 34.

[2]. Deming Mei (2018). Cultivate newcomers with Chinese feelings, international horizon and cross-cultural communication skills- the subject educational beliefs and realization path of English Curriculum Standards for Senior High School (2017 Edition) [J]. People's Education. (11):46-49.

[3]. Guming Xia (2018). Connotation Analysis of Thinking Quality as one of the core competencies of English subject [J]. Journal of Xingyi National Normal University. (3): 84-87.

[4]. Haiping Gong (2018). Cultivation of Culture Consciousness of English Language in English Teaching [J].Foreign Languages and Their Teaching. (8): 42-44.

[5]. Shike Cheng (2019). Senior High School English Reading Teaching Practice Based on the Activity View of English Learning [J]. Journal of Basic Education Curriculum. (7): 50-56.

[6]. The Ministry of Education of the People's Republic of China (2017). English Curriculum Standards for Senior High School [M]. Beijing, People's Educational Press.

[7]. Xiaotang Cheng \& Siqi Zhao (2016). The Essential Connotation of core competencies of English subject [J]. Curriculum, Teaching Material and Method. (36):79-86. 